\title{
Blockage of axonal transport induced by acute, graded compression of the rabbit vagus nerve
}

\author{
B RYDEVIK*, W G McLEAN + , J SJÖSTRAND $\dagger_{+}^{+}$, AND G LUNDBORG*§ \\ From the * Laboratory of Experimental Biology, Department of Anatomy, $\dagger$ Institute of Neurobiology, \\ $\dagger+$ Department of Ophthalmology, ${ }^{*} \S$ Division of Hand Surgery, Department of Orthopaedic Surgery I, \\ University of Göteborg, Göteborg, Sweden
}

SUMMARY Rapid axonal transport in rabbit vagus nerve was studied during and after graded nerve compression. Proteins of the rapid axonal transport were labelled by micro-injection of ${ }^{3} \mathrm{H}$-leucine into the nodose ganglion and the cervical vagus nerve was subjected to graded compression by a small "mini-cuff" applied directly to the exposed nerve trunk. The results showed that even slight trauma to the nerve, in this model represented by a pressure at $50 \mathrm{mmHg}$ applied for two hours, may induce accumulation of axonally transported proteins at the level of compression. This transport block was, however, reversible within one day. $200 \mathrm{mmHg}$ and $400 \mathrm{mmHg}$ applied for two hours similarly induced a block of axonal transport persisting up to at least one and three days respectively after the compression. Time for recovery of normal transport was correlated with the magnitude of the pressure applied to the nerve. The results indicate that axons may survive, that is not undergo Wallerian degeneration, after blockage of rapid axonal transport persisting at least one day after the compression trauma.

Within the axons of peripheral nerves there is continuous transport of various substances, for example proteins and organelles, from the nerve cell body down to the axon terminals (anterograde axonal transport) as well as in the opposite directicn (retrograde axonal transport). The phenomenon of axonal transport was first described by Weiss and Hiscoe, ${ }^{1}$ who found swelling of axons proximal to a constriction. Later investigations have demonstrated the existence of anterograde axonal transport at well defined different rates in primate peripheral nerves ranging from about $1 \mathrm{~mm} /$ day (slow phase) to approximately $400 \mathrm{~mm} /$ day (rapid phase). ${ }^{2-7}$

Interference with the axonal transport systems has been demonstrated in association with various kinds of neuropathies based upon, for example, toxic, ischaemic and traumatic affections of peripheral nerves. ${ }^{7-9}$ However, the possible role of impairment of axonal transport in the development of functional disorders of nerves

Address for reprint requests: Dr B Rydevik, Laboratory of Experimental Biology, Department of Anatomy, University of Göteborg, P.O. Box 33031, S-400 33 Göteborg, Sweden.

Accepted 20 March 1980 is still not fully understood. ${ }^{10}$ At present we do not know either how sensitive axons are to minor impairment of axonal transport in an anterograde or retrograde direction, or how chronic these changes must be in order to cause axonal degeneration.

Peripheral nerves can be subjected to various types of acute as well as chronic compression trauma, which often result in functional disturbances, for example in association with nerve entrapment syndromes and injury to extremities. The pathophysiological basis for such nerve compression syndromes may be highly complex as these lesions affect all tissue components of the nerve trunk, that is nerve fibres, intraneural blood vessels and connective tissue. These structures respond to trauma in various ways and may therefore-separately or together - play various roles in the post-traumatic pathophysiology. ${ }^{11-13}$

The involvement of axonal transport systems in association with compression and ischaemia of varying duration has been studied by $\mathrm{Ochs}^{6}{ }^{7}$ and Leone and Ochs. ${ }^{8}$ Those authors inflated tourniquets around the thighs of cats and found that the rapid axonal transport of the sciatic 
nerve was arrested at the level of cuff compression. The transport block was reversible as long as the tourniquet was not applied for more than six to seven hours. In vitro experiments demonstrated that rapid axonal transport was impaired within 15 minutes of onset of anoxia. ${ }^{8}$ Recovery' to normal transport was obtained when $\mathrm{O}_{2}$ was re-supplied after the in vitro anoxia up to 1.5 hours duration but not after two hours. Hahenberger $^{14}$ has demonstrated that pressure applied to rabbit vagus nerve in vitro may block axonal transport. Experimental elevation of intraocular or intracranial pressure has been shown to in. duce blockage of axonal transport in the optic nerve of monkeys. ${ }^{15-19}$ The information available in the literature on the reaction of axonal transport systems of peripheral nerves to graded and controlled compression trauma, however, is incomplete.

The aims of the present investigation were (1) to study rapid anterograde axonal transport during graded compression, in order to determine the extent of acute blockage of axonal transport in nerves subjected to various degrees of pressure, and (2) to study the reversibility of blockage of axonal transport induced by nerve compression of various magnitudes.

\section{Material and methods}

Seventy-six albino rabbits of both sexes, weighing $1 \cdot 8-2.5 \mathrm{~kg}$, were used. Anaesthesia was induced by intravenous infusion of sodium pentobarbital (Mebumal, ${ }^{\circledR} 25-30 \mathrm{mg} / \mathrm{kg}$ ) into a marginal ear vein and intraperitoneal injection of diazepam (Valium, ${ }^{\circledR} 2 \mathrm{mg} / \mathrm{kg}$ ). Anaesthesia was maintained by additional iv injections of sodium pentobarbital when necessary.

\section{Compression}

A 30 to $40 \mathrm{~mm}$ length of the vagus nerve was exposed in a region 10 to $50 \mathrm{~mm}$ from the nodose ganglion, with the rabbit lying immobilised in a supine position. Nerves were compressed by application of a specially constructed apparatus consisting of a plexiglass chamber containing a pair of rubber membranes. The two halves of the chamber were secured in place by screws on either side of the vagus nerve in such a way that the nerve lay in a groove in the plexiglass and in contact with the membranes (fig 1). The chamber was inflated with air to the desired pressure as read on a manometer, and the nerve was thus compressed between the rubber membranes. The length of the compressed nerve segment was 10

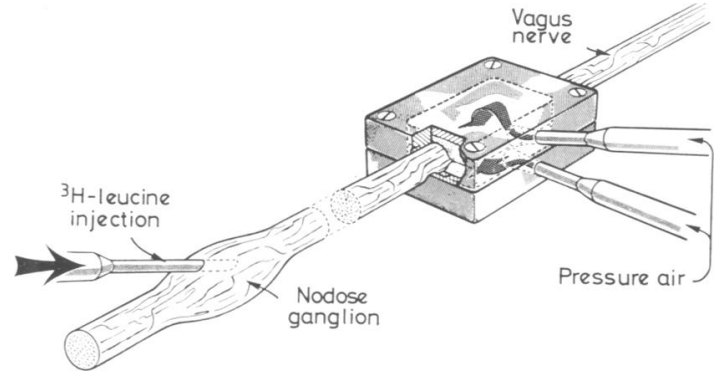

Fig 1 Schematic drawing of experimental procedure. Axonally transported proteins were labelled by injection of ${ }^{3} \mathrm{H}$-leucine into the nodose ganglion. In acute experiments, the labelling was performed 2 hours before application of the compression chamber around the cervical vagus nerve. The chamber, consisting of plexiglass and rubber membranes, was inflated with air to a known pressure (50-200-400 $\mathrm{mmHg}$ ) during 2 hours. In other experiments, a recovery period from 1 up to 14 days after the compression was allowed before labelling of proteins was performed.

$\mathrm{mm}$. The pressure in the chamber was maintained at a constant level throughout the experiments by a special air pump, compensating for any leak in the system.* Surrounding muscle and skin were loosely sutured in place for the remainder of the compression period, during which time the rabbit remained anaesthetised. Possible effects of the chamber application per se were investigated in sham experiments (Series A-sham experiments, $n=11$ ). In these cases axonal transport was measured when the chamber was applied around the nerve in the usual way but without being connected to the pressure system. Control experiments (Series A-control experiments, $n=6$ ) were performed by measuring axonal transport of labelled proteins as described below without any chamber application at all. Nerves were removed four hours after labelling and processed in the ordinary way.

The effect of compression for two hours at three pressure levels was investigated: $50 \mathrm{mmHg}$ (Series B, n=12), $200 \mathrm{mmHg}$ (Series $\mathrm{C}, \mathrm{n}=22$ ) and $400 \mathrm{mmHg}$ (Series $\mathrm{D}, \mathrm{n}=25$ ). $1 \mathrm{mmHg}=$ 133:4 Pascal. In some of the experiments axonal transport was studied during compression, and in others there was a recovery period ranging from one to 14 days after compression, before axonal transport was measured (see also below: Axonal transport). In order to keep the body temperature constant, the animals were placed on insulating cushions. Local temperature close to the chamber was recorded in four experi-

*AB Stille-Werner, P.O. Box 43051, S-100 72 Stockholm, Sweden. 
ments and was found to be 37 to $38^{\circ} \mathrm{C}$. Further details of the compression procedure have been published previously. ${ }^{13}$

\section{Axonal transport}

The rapid axonal transport of ${ }^{3} \mathrm{H}$-labelled proteins was measured as described previously. ${ }^{20}$ The nodose ganglion was exposed and $200 \mu l$ $(100 \mu \mathrm{Ci})$ of ${ }^{3} \mathrm{H}$-leucine in $0.9 \% \mathrm{NaCl}(\mathrm{L}-4.5$ "H-leucine $53 \mathrm{Ci} / \mathrm{mmole}$, Radiochemical Centre, Amersham, England) were injected subepineurially into the nodose ganglion via a 30-gauge stainless steel hypodermic needle. In acute experiments (that is without recovery from compression) vagus nerves were compressed two hours after labelling with ${ }^{3} \mathrm{H}$-leucine; in others recovery from compression of up to 14 days was allowed before proteins were labelled. In all cases the rabbit was killed four hours after injection of isotope. That time was chosen to allow for synthesis of protein in the ganglion, transport along the cervical vagus nerve and accumulation of radiolabelled proteins in the case of a transport block caused by the local compression. The nodose ganglion and up to 80 $\mathrm{mm}$ of the vagus nerve were immediately removed and transferred to ice. The nerve was then cut into $2.5 \mathrm{~mm}$-length pieces and the pieces were individually soaked in $2 \mathrm{ml} 10 \%$ trichloro-acetic acid (TCA) for 24 hours at $4^{\circ} \mathrm{C}$. The TCA was discarded, nerve pieces were washed in a further $2 \mathrm{ml}$ cold TCA and dissolved overnight at room temperature in $0.5 \mathrm{ml}$ Soluene ${ }^{\circledR}$ (Packard). Radioactivity in the dissolved nerve pieces was measured in $10 \mathrm{ml}$ Permablend ${ }^{8}$ (Packard) scintillation fluid in a Packard Tri-carb liquid scintillation counter with automatic quench correction. Since the TCAsoluble radioactivity was consistently less than $5 \%$ of the total radioactivity in the nerve pieces, the TCA wash was dispensed with in later experiments, and the nerve pieces were immediately dissolved in Soluene.

\section{Calculation of results}

The radioactivity in each nerve piece was plotted

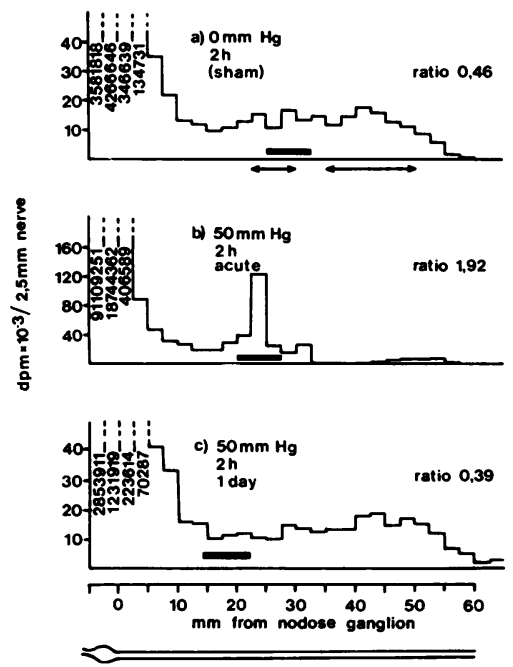

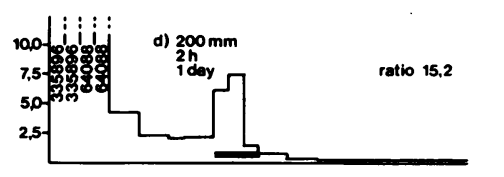
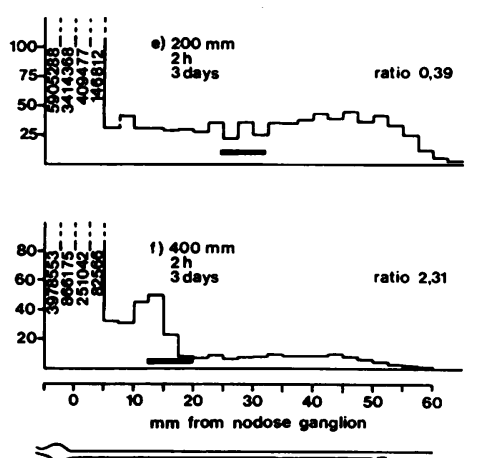

Fig 2 a-f Summa:y of typical findings in various experimental series. Pressure, time of application, recovery period and transport block ratio (see text pages 691-3) is shown in each diagram. A black bar indicates the site of compression. The arrows in fig $2 a$ indicate segments of nerve used for calculation of transport block ratio (see pages 692-3). Application of chamber around the nerve for 2 hours without inflation (sham experiments) caused no or just a minimal accumulation of axonally transported proteins (fig 2a), in contrast to $50 \mathrm{mmHg}$ applied for 2 hours which caused a block of axonal transport (fig 2b). This block was reversible within one day (fig 2c). In the experiment shown in fig 2d, a block of axonal transport was persisting one day after compression by $200 \mathrm{mmHg}$ for 2 hours. After a three day recovery period, normal transport was found (fig 2e). In cases of compression by $400 \mathrm{mmHg}$ for 2 hours a blockage of transport was seen even 3 days after the trauma (fig 2f). 
against the distance of the piece from the nodose ganglion. This gave a profile of the distribution of labelled proteins in the vagus nerve four hours after injection of ${ }^{3} \mathrm{H}$-leucine into the nodose ganglion. In untreated nerves, a wavefront of labelled proteins appeared about $60 \mathrm{~mm}$ from the ganglion, indicating a rate of axonal transport of at least $360 \mathrm{~mm} /$ day, in agreement with previous studies. ${ }^{20}$ In nerves in which compression had blocked axonal transport, an accumulation of labelled proteins was found in the nerve in the region of the compression. By drawing profiles of the radioactivity in nerves from each experiment we were able to estimate the extent to which compression had blocked axonal transport. Nerves were classed into three groups:

(a) those having a normal profile, that is having a wavefront of proteins comparable to that of control nerves see for example (figs 2 a and c), (b) those showing a partial block of axonal transport, that is having accumulation of axonally transported protein at the level of compression but also a wavefront distal to the compression zone (see for example fig $2 \mathrm{f}$ ),

(c) those showing a complete block, that is having accumulation of axonally transported proteins at the level of the compression and no wavefront distal to this level (see for example fig $2 \mathrm{~d}$ ).

A more objective assessment of the blockade of transport was obtained by the calculation of a "transport block ratio" for each nerve. This was achieved by expressing the radioactivity contained in three $2.5 \mathrm{~mm}$ nerve pieces, one immediately proximal to the region of compression and two in proximal $5 \mathrm{~mm}$ of the compression region, as a fraction of the radioactivity contained in six $2.5 \mathrm{~mm}$ nerve pieces situated at the level of the peak of transported proteins, that is between $37.5 \mathrm{~mm}$ and $52.5 \mathrm{~mm}$ frcm the ganglion (see fig 2 a). Nerves exhibiting a normal transport profile and wavefront of labelled proteins generally had transport block ratio less than $0 \cdot 5$. Nerves in which labelled proteins had accumulated at the compression zcne had higher transport block ratio. Generally, the higher the transport block ratio, the greater was the block of axonal transport.

\section{Results}

The results are summarised in the table. The distribution of radioactively labelled proteins along the vagus nerves four hours after injection of ${ }^{3} \mathrm{H}$-leucine into the nodose ganglia is illustrated in fig 2. In sham-operated nerves (fig 2 a), in which the compression chamber was applied for two hours but not inflated, and in untreated control nerves (results not shown) a wave of labelled proteins was found with a front about $60 \mathrm{~mm}$ from the ganglion. This wavefront was a result of axonal transport of proteins radiolabelled in the nodose ganglion, as demonstrated by the fact that the contralateral vagus nerve which was exposed to a similar amount of bloodborne ${ }^{3} \mathrm{H}$-leucine did not show any such profile of radioactivity, and also by the fact that only $5 \%$ of the radioactivity was TCA-soluble, that is not of high molecular weight. The accumulation of the labelled material at an area of compression also confirms the fact that the movement of the wave was an active process.

The total amount of radioactivity incorporated in the nerves varied from experiment to experiment, depending on the effectiveness of the injection. Comparison of fig $2 \mathrm{~d}$, in which the average $\mathrm{dpm}$ in normal nerve pieces was around $2.5 \times 10^{3}$, with fig $2 \mathrm{~b}$, in which the radioactivity was more than ten times greater, demonstrates that variations of the absolute amount of radioactivity in the nerve within this range did not affect the shape of the profile. Nerves which had an average $\mathrm{dpm}$ of less than $1.0 \times 10^{3}$ were, however, rejected.

Series A: Sham experiments $(0 \mathrm{mmHg}-2$ hours, $n=11)$ and untreated control nerves $(n=6)$

Application of the chamber around the nerve for two hours without inflation induced a slight accumulation of axonal transport in some nerves, while others had a completely normal transport (table, fig 2 a). The slight accumulation found in some nerves in this series is reflected in the increased mean value of transport block ratio $( \pm \mathrm{SEM}): 0 \cdot 71 \pm 0 \cdot 10$, as compared to untreated control nerves: $0.38 \pm 0.02$.

\section{Series B: $50 \mathrm{mmHg}-2$ hours $(n=12)$}

Acute compression (without recovery) at 50 $\mathrm{mmHg}$ for two hours induced accumulation of axonally transported proteins in all nerves $(n=5$; see fig 2 b). The transport block was partial in four nerves and complete in one nerve (mean transport block ratio: $2 \cdot 46 \pm 1 \cdot 17$; see also table). Recovery of axonal transport to normal values was found as early as one day after the compression $(n=4$; see fig 2 c). Normalised transport block ratios were also obtained after 3 days $(n=3$; see table).

Series C: $200 \mathrm{mmHg}-2$ hours $(n=22)$

Acute compression at $200 \mathrm{mmHg}$ for two hours 
Table Demonstration of transport block ratio values $\pm S E M$ obtained in the various experimental series (for details see text). Generally, the higher the transport block ratio, the greater was the block of axonal transport. Transport block ratio values lower than 0.5 usually indicated normal axonal transport

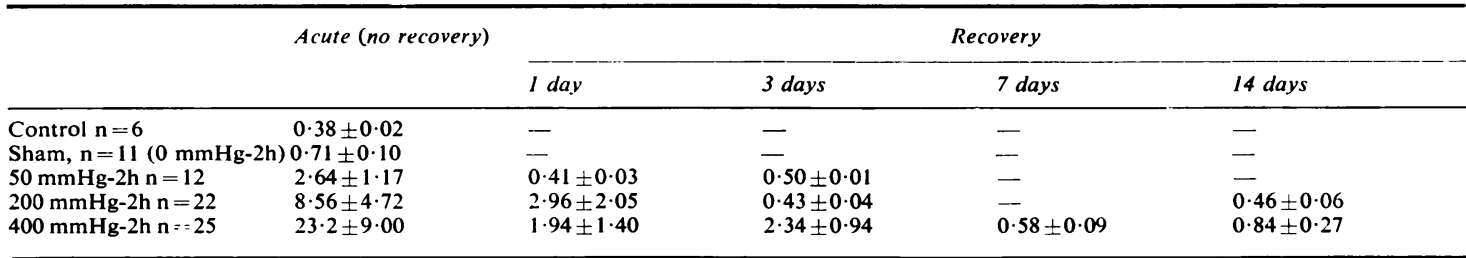

induced acute accumulation in all cases $(n=4)$, the block being partial in two nerves and complete in two nerves. The mean value of transport block ratio was $8.56 \pm 4.72$ which indicates a higher degree of acute accumulation in these nerves than in the $50 \mathrm{mmHg}-2$ hours compression nerves (table).

The peak of the acute accumulation was mainly located at the proximal (cranial) edge of the compression zone. In this series, transport recovered completely in some nerves after one day, while others still showed a block of transport at this time $(n=7$; see fig 2 d). However, mean transport block ratio values were not normalised until after 3 days of recovery from compression at $200 \mathrm{mmHg}$ for two hours $(\mathrm{n}=5$; see fig 2 e). Some nerves still showed a partial block after three days and even after 14 days recovery $(n=6)$, although the accumulation was very slight and transport block ratios were less than 0.7 in these nerves (table).

Series D: $400 \mathrm{mmHg}-2$ hours ( $n=25$ )

Compression at $400 \mathrm{mmHg}$ for two hours induced complete acute block in all nerves $(n=3$, transport block ratio $23 \cdot 2 \pm 9 \cdot 00$ ), the accumulation of labelled proteins again being most pronounced at the proximal (cranial) edge of the compressed nerve segment. The pattern of recovery was more complex in this series (see table); transport in two nerves out of six had recovered completely one day after compression, but after a three day period there were various degrees of protein accumulation at the level of compression in all six nerves tested (see for example, fig $2 \mathrm{f}$ ). Five out of ten nerves still showed a partial block of transport at seven and 14 days after compression, while transport was normalised in the other nerves at those times.

The mean values of transport block ratios of all nerves compressed at 50,200 and $400 \mathrm{mmHg}$ for two hours, as measured at various times in relation to the compression, are demonstrated in fig 3 .

\section{Discussion}

Blockage of axonal transport during compression Rapid axonal transport is an energy dependent process $^{6}$ which is blocked by ischaemia in vivo, as demonstrated for example in cat sciatic nerves by tourniquet compression of the hind limb and by anoxia in vitro. ${ }^{6-8}$ Two main factors may be involved in producing axonal transport block during compression of a peripheral nerve:

(1) Ischaemia of the compressed nerve segment due to occlusion of vasa nervorum. and

(2) Mechanical deformation of the nerve fibres.

Our results show that even as low pressure as $50 \mathrm{mmHg}$ applied for two hours may acutely block rapid axonal transport of rabbit vagus nerve to a considerable degree (table, fig 2 b). The mechanism behind accumulation of axonal transport induced by such low pressure is not known. We know, however, that compression of rabbit peripheral nerve by 50 $\mathrm{mmHg}$ causes occlusion of the major pait of the intraneural microvessels, thus rendering the compressed nerve segment almost completely ischaemic. ${ }^{21}$ Since ischaemia is known to block rapid axonal transport ${ }^{8}$ it seems justified to assume that the transport block induced by $50 \mathrm{mmHg}$ compression is caused by ischaemia of the compressed nerve segment. This assumption is further supported by the fact that the block is comparatively rapidly reversible (see below: Reversibility of axonal transport block). Some degree of nerve fibre deformation might, however, also contribute to axonal transport blockage at this pressure level. ${ }^{14}$ One should notice that even sham application of the chamber induced some slight accumulation of axonal transport, as compared to the control nerves (table) indicating that even minor trauma to a nerve may to some extent impair rapid axonal transport.

When higher pressure was applied to the nerves, that is 200 and $400 \mathrm{mmHg}$ for two hours, 
a correspondingly greater block of transport was induced; the accumulation of axonally transported material was more complete in those nerves, as reflected in the higher values of transport ratio (table). When 200 and $400 \mathrm{mmHg}$ were applied, the compressed nerve segment was rendered completely ischaemic, since the pressure in the compression-chamber was well above systolic blood pressure. ${ }^{21}$ This might explain why the transport block was more complete in these nerves than in the $50 \mathrm{mmHg}$ compression cases, in which there was less than total ischaemia. There is, however, also considerable deformation of the nerve trunk and its contents, when nerves are compressed directly at 200 and 400 $\mathrm{mmHg}^{1322}$ and mechanical distortion of nerve fibres is probably also an important factor in producing transport block at these higher pressure levels. Compression at $400 \mathrm{mmHg}$ for two hours induced a higher degree of transport block than did $200 \mathrm{mmHg}$ for two hours. Between these two groups of experiments there was probably no difference in the degree of ischaemia, but nerve fibre deformation may well have been more extensive at the highest pressure level $(400 \mathrm{mmHg})$, leading to a more complete accumulation of labelled proteins during compression of these nerves.

\section{Reversibility of axonal transport blockage}

In the present series ff experiments there were marked differences in the time for recovery of normal transport after compression by 50, 200 and $400 \mathrm{mmHg}$, respectively, applied for two hours. In nerves compressed by $50 \mathrm{mmHg}$ for two hours there was a rapid recovery, and normal transport profiles and ratios were found as early as the first day after the compression (table, fig 2 c). This rapid recovery indicates that the cause of the block induced at this pressure level is reversible ischaemia and not major deformation and injury of axons. Our results are in good agreement with those of Leone and $\mathrm{Ochs}^{8}$ who in their investigations also found recovery of normal transport one day after two hours tourniquet ischaemia in vivo. The compression factor in various situations is discussed below on page 696 .

In our experiments, 200 and $400 \mathrm{mmHg}$ applied for two hours induced prolonged transport block, persisting up to one and three days, respectively, and in some cases even up to 14 days postoperatively (table; figs $2 \mathrm{~d}$, e, f and 3 ). When discussing the mechanism behind such prolonged block of axonal transport induced by compression trauma, one should consider the reaction of various intraneural tissues to trauma and possible interactions between nerve fibres and the supporting tissue elements of the nerve trunk.

The intraneural microvessels may respond to injury by increased permeability resulting in oedema formation. ${ }^{13}{ }^{23}$ It has been shown that compression of peripheral nerves by $200-400$ $\mathrm{mmHg}$ for two hours may induce intraneural microvascular injury with subsequent oedema

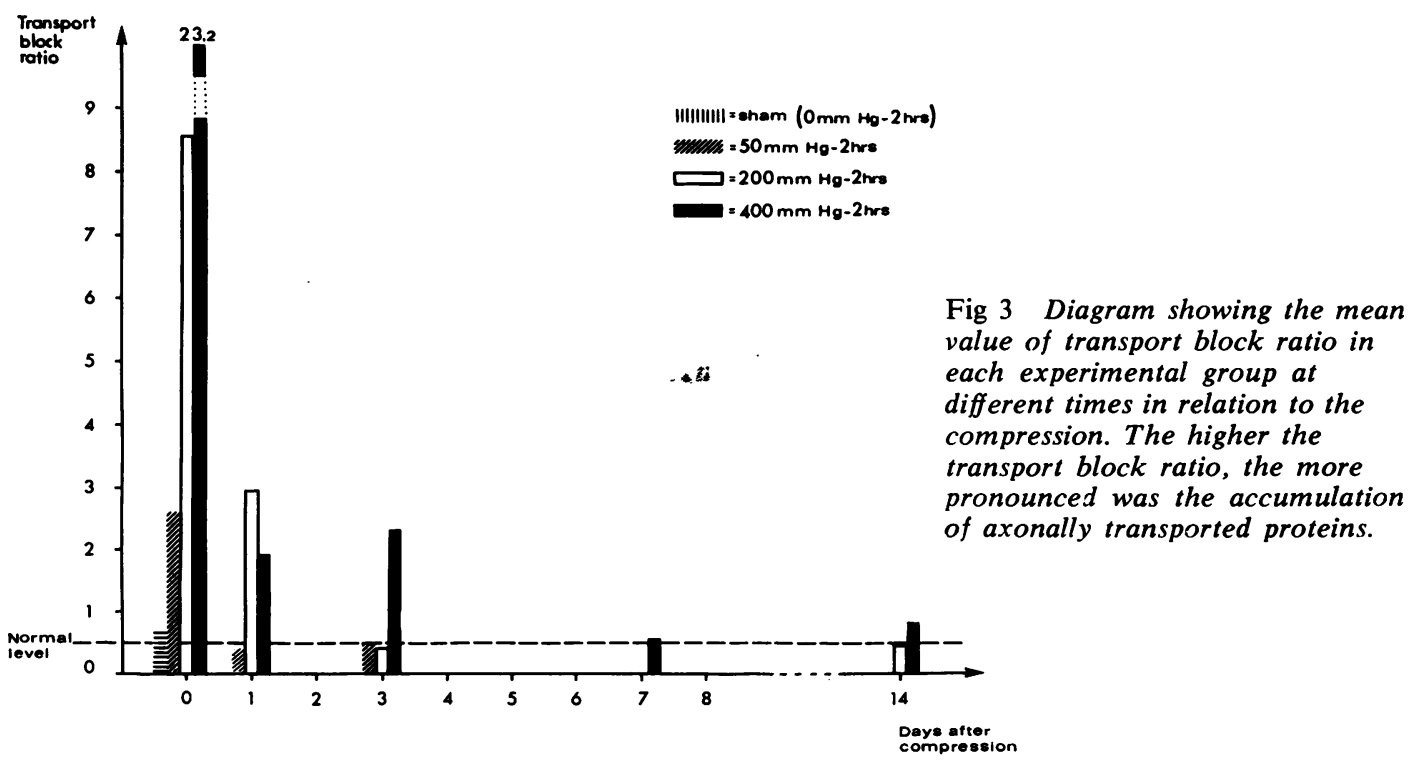


formation among the axons in the endoneurial space. ${ }^{13}$ An endoneurial oedema may alter the local environment of the axons by disturbing the ionic balance in the endoneurium. This may possibly impair rapid axonal transport, which is known to be influenced by alterations in local ion concentration. ${ }^{24}$ Endoneurial oedema may also lead to increased endoneurial pressure because of the unyielding properties of the perineurium, as demonstrated in association with experimental lead neuropathy ${ }^{25}$ and experimental hexachlorophene neuropathy. ${ }^{26} \mathrm{~A}$ posttraumatic increase of endoneurial pressure due to oedema formation in the nerve may lead to prolonged occlusion of endoneurial capillaries, thus leading to a persisting ischaemia even after the pressure in the compression-cuff has been released. ${ }^{21}$ Such long-lasting ischaemia may also influence axonal transport.

Mechanical deformation of the nerve fibres has been shown to be of significance in the pathophysiology of acute nerve compression lesions. ${ }^{27}{ }^{28}$ Compression of nerve fibres may thus lead to deformation and various degrees of injury of myelin sheaths ${ }^{2 i}$ and one might also expect the trauma to affect axonal membranes, as well as subcellular axoplasmic components suggested to be involved in axonal transport, for example smooth endoplasmic reticulum ${ }^{29} 30$ and microtubules. ${ }^{61}$ If pressure locally applied on peripheral nerves is high enough, one might expect not only collapse of the axon but also pronounced deformation of the nerve fibres beneath the edges of the compression cuff. ${ }^{22}{ }^{2 i}$ Such mechanical deformation may lead to persistent structural changes of the axon and its subcellular content. This was probably the case in our experiments where nerves were compressed at $400 \mathrm{mmHg}$ for two hours, because in some of these nerves there was a prolonged transport block, persisting up to 14 days after the compression (table).

There are some other reports on recovery of axonal transport after blockage induced by, for example, cooling ${ }^{3132}$ or colchicine application. ${ }^{33}$ It is clear that axonal transport can recover from blockage without nerve regeneration, and it has been calculated that neuronal degeneration need not occur even after six weeks axonal transport block induced by colchicine. ${ }^{33}$ Ochs $^{7}$ and Leone and Ochs ${ }^{8}$ studied the reversibility of axonal transport block produced by in vivo application of tourniquets around cat hind limbs. The pressure in the cuff was kept constant at $300 \mathrm{mmHg}$ and the time of application varied from two up to eight hours. The results showed reversibility of transport blockade even after six hours of tourniquet compression. This might seem to contradict our results, which demonstrated that direct compression of nerves at 200 $400 \mathrm{mmHg}$ for two hours induced transport blockage persisting up to at least one to three days after compression. In the experiments by Ochs $^{7}$, however, a tourniquet was applied around the intact limb and the quality of compression trauma may not be compatible when nerves are compressed in these two different ways. In our experiments the pressure was applied directly to the nerve, a technique which probably involves more pronounced deformation of the nerve under the edges of the compression chamber. A more extensive discussion of these factors is, however, beyond the scope of this work.

In the present investigation we have studied the effects of compression on axonal transport in the sensory fibres of rabbit vagus nerve. This fibre population mainly consists of small, unmyelinated fibres. ${ }^{34}$ It is known that small nerve fibres undergo less deformation than larger fibres at a given pressure ${ }^{35}$ and that sensory functions mediated by small nerve fibres, for example pain, are affected late in the course of clinical compression neuropathies. ${ }^{38}$ This means that our findings, obtained in the small, unmyelinated vagal nerve fibres could be more pronounced in other nerves consisting mainly of larger myelinated nerve fibres.

\section{Functional and clinical implications of axonal transport block}

The results from the present investigation show that even as low pressure as $50 \mathrm{mmHg}$ applied locally on a nerve for two hours may induce acute block of axonal transport. Pressure well above this level has been recorded experimentally in the human carpal tunnel. ${ }^{37}$ Our results thus support experimental data and clinical observations indicating that axonal transport may be impaired to a considerable extent in association with chronic compression lesions of peripheral nerves. ${ }^{38} 39$ Prolonged impairment of axonal transport may affect the functional and structural integrity of the distal part of axon ${ }^{3340}$ as well as the trophic effects on the target cells of the axon, for example muscle tissue. ${ }^{41}$

It is interesting to notice that our findings indicate that axons may survive distal to a block of axonal transport, persisting at least one day, without Wallerian degeneration to occur.

In this context we would like to consider the "double-crush"-hypothesis presented by Upton and McComas $^{39}$ and McComas et al. ${ }^{42}$ These 
authors suggested that axons that were compressed at one level, for example in the region of the cervical spine, could be deprived of some axonally transported material due to the compression, and that the axons thereby would become more sensitive to an additional compressicn trauma induced to the nerve at a distal level, for example carpal tunnel compression of the median nerve. This hypothesis was based on clinical observation that the majority $(71 \%)$ of a group of patients with carpal tunnel syndrome also had an associated neural lesion in the neck. Our findings in nerves compressed at low pressure $(50 \mathrm{mmHg})$ support, as discussed above, the assumptions by Upton and $\mathrm{McComas}^{39}$ that axonal transport may be blocked in association with clinical compression of spinal nerves and entrapment of nerve trunks in extremities. The hypothesis that the part of an axon located distal to a compression should become more sensitive to another compression trauma has, however, not to our knowledge been substantiated by any experimental data.

Williams and Gilliatt ${ }^{43}$ studied the regeneration of nerve fibres distal to a neurapraxic compression lesion in baboons. They found no differences in the rate of regeneration between the control nerves and the nerves subjected to a proximal compression lesion a few days before the distal crush injury. They concluded that this finding indicated that the axonal transport systems were not impaired more than a few days after acute tourniquet compression, an assumption which is in accordance with our results. Discrepancies in results due to differences in pressure level and mode of pressure application have been discussed previously (p. 696).

The present study has, in conclusion, demonstrated that even a slight compression trauma to nerves may induce acute accumulation of s xonally transported material. Time for recovery of normal transport after compression was related to the magnitude of the pressure applied to the nerves.

This work was supported by grants from the Swedish Medical Research Council (projects nr 5188 and 2226), the Faculty of Medicine, University of Göteborg, the Göteborg Medical Society and the Swedish Work Environment Fund.

\section{References}

1 Weiss $P$, Hiscoe HB. Experiments on the mechanism of nerve growth. J Exp Zool 1948;
107:315-95.

2 Lubińska L. Axoplasmic streaming in regenerating and in normal nerve fibres. Prog Brain Res 1964; 13:1-71.

3 Dahlström A, Häggendal J. Some quantitative studies on the noradrenaline content in the cell bodies and terminals of sympathetic adrenergic neuron system. Acta Physiol Scand 1966; 67:271-7.

4 McEwen BS, Grafstein B. Fast and slow components in axonal transport of protein. J Cell Biol 1968; 38:494-508.

5 Karlsson JO, Sjöstrand J. Synthesis, migration and turnover of protein in retinal ganglion cells. J Neurochem 1970; 18:749-67.

6 Ochs S. Energy metabolism and supply of $\sim P$ to the fast axoplasmic transport mechanism in nerve. Fed Proc 1974; 33:1049-58.

7 Ochs S. Axoplasmic transport-a basis for neural pathology. In: Peripheral Neuropathy. Vol. 1. Dyck PJ, Thomas PK, Lambert EH, eds. Philadelphia: Saunders, 1975: Chapter 12, 213-30.

8 Leone J, Ochs S. Anoxic block and recovery of axoplasmic transport and electrical excitability of nerve. J Neurobiol 1978; 9:229-45.

9 Sjöstrand J, Frizell M, Rydevik B. Changes in axonal transport in various experimental neuropathies. In: Peripheral Neuropathies. Canal N, Pozza G, eds. Amsterdam: Elsevier North Holland Biomedical Press, 1978: 147-57.

10 Sjöstrand J. McLean WG, Frizell M. The application of axonal transport studies to peripheral nerve problems. In: Management of Peripheral Nerve Problems. Omer GE, Spinner M, eds. Philadelphia: WB Saunders Company, 1980: 917-27.

11 Lundborg G. Ischaemic nerve injury. Experimental studies on intraneural microvascular pathophysiology and nerve function in a limb subjected to temporary circulatory arrest. Scand J Plast Reconstr Surg 1970: Suppl. 6.

12-Rydevik B, Brånemark P-I, Nordborg C, McLean WG, Sjöstrand J, Fogelberg M. Effects of chymopapain on nerve tissue. An experimental study on the structure and function of peripheral nerve tissue in rabbits after local application of chymopapain. Spine 1976; 1:137-48.

13 Rydevik B, Lundborg G. Permeability of intraneural microvessels and perineurium following acute, graded experimental nerve compression. Scand J Plast Reconstr Surg 1977; 11:179-87.

14 Hahnenberger RW. Effects of pressure on fast axoplasmic flow. An in vitro study in the vagus nerve of rabbits. Acta Physiol Scand 1978; 104:299-308.

15 Levy NS. The effects of elevated intraocular pressure on slow axonal protein flow. Invest Ophthalmol Vis Sci 1974; 13:691-95.

16 Anderson DR, Hendrickson A. Effect of intraocular pressure on rapid axoplasmic transport in monkey optic nerve. Invest Ophthalmol Vis Sci 
1974; 13:771-83.

17 Quigley HA, Anderson DR. The dynamics of axonal transport blockade by acute intraocular pressure elevation in primate optic nerve. Invest Ophthmol Vis Sci 1976; 15:606-16.

18 Minckler DS, Bunt AH, Johanson GW. Orthograde and retrograde axoplasmic transport during acute ocular hypertension in the monkey. Invest Ophthalmol Vis Sci 1977; 16:426-41.

19 Tso MOM, Hayreh SS. Optic disc edema in raised intracranial pressure. Arch Ophthalmol 1977; 95:1458-62.

20 McLean WG, Frizell M, Sjöstrand J. Slow axonal transport of proteins in sensory fibres of rabbit vagus nerve. $J$ Neurochem 1976; 26:1213-6.

21 Rydevik B, Lundborg G, Bagge U. Effects of graded compression on intraneural blood flow. $J$ Hand Surg 1980; (in press).

22 Rydevik B, Nordborg C. Changes in nerve function and nerve fibre structure induced by acute graded compression. An experimental study on early and late effects in rabbit tibial nerve. J Neurol Neurosurg Psych 1980. (In press.)

23 Olsson Y. Studies on vascular permeability in peripheral nerves. I. Distribution of circulating fluorescent serum albumin in normal, crushed and sectioned rat sciatic nerve. Acta Neuropathol (Berl) 1966; 7:1-15.

24 Edström A. Ionic requirements for rapid axonal transport in vitro in frog sciatic nerves. Acta Physiol Scand 1975; 93:104-11.

25 Low PA, Dyck PJ. Increased endoneurial fluid pressure in experimental lead neuropathy. Nature 1977; 269:427-8.

26 Powell HC, Myers RR, Zweifach BW, Lampert PW. Endoneurial pressure in hexachlorophene neuropathy. Acta Neuropathol (Berl) 1978; 41: 139-44.

27 Ochoa J, Fowler TJ, Gilliatt RW. Anatomical changes in peripheral nerves compressed by a pneumatic tourniquet. J Anat 1972; 113:3, 43355.

28 Fowler TJ, Danta G, Gilliatt RW. Recovery of nerve conduction after a pneumatic tourniquet: Observations on the hind-limb of the baboon. J Neurol Neurosurg Psychiatry 1972; 35:638-47.

29 Droz B, Di Giamberardino L, Koenig HL. Transports axonaux de macromolecules présynaptiques. Actual Neurophysiol 1974; 10:236-60.

30 Markov D, Rambourg A. Droz B. Smooth endoplasmic reticulum and fast axonal transport of glycoproteins. An electron microscopic radioautograph study of thick sections after heavy metals impregnation. J Microscop Biol Cell (Paris) 1976; 25:57-60.

31 Banks P, Till R. A correlation between the effects of anti-mitotic drugs on micro-tubule assembly in vitro and the inhibition of axonal transport in noradrenergic neurones. J Physiol (Lond) 1975; 252:283-94.

32 Brimijoin S, Helland L. Rapid retrograde transport of dopamine- $\beta$-hydroxylase as examined by the stop-flow technique. Brain Res 1976; 102:217-28.

33 Cuénod $M$, Boesch $J$, Marlio $P$, Perisic $M$, Andvi C, Schonbach J. Contribution of axoplasmic transport to synaptic structures and functions. Int Neurosci 1972; 4:77-87.

34 Evans DHL, Murray JG. Histological and functional studies on the fibre composition of the vagus nerve of the rabbit. J Anat 1954; 88: 320-36.

35 McGregor RJ, Sharpless SK, Luttges MW. A pressure vessel model for nerve compression. J Neurol Sci 1975; 24:299-304.

36 Sunderland S. Nerves and nerve Injuries. Edinburgh: Churchill Livingstone, 2nd ed, 1978.

37 Smith EM, Sonstegard DA, Andersson WH. Carpal tunnel syndrome: Contribution of flexor tendons. Arch Phys Med Rehabil 1977; 58: 379-85.

38 Catalano F, Logroscino CA. Studio del flusso assoplasmatico con impiego di radioisotopi e sue modificazioni in rapporto ad alcuni tipi de lesioni traumatiche dei nervi periferici. Clin Ortop (Parma) 1972; 23:159-63.

39 Upton RM, McComas AJ. The double crush in nerve entrapment syndromes. Lancet 1973; 2: 359-62.

40 Miledi R, Slater CR. On the degeneration of $\mathrm{tat}$ neuromuscular junctions after nerve section. J Physiol (Lond) 1970; 207:507-28.

41 Guth L. Trophic influences of nerve on muscle. Physiol Rev 1968; 48:645-87.

42 McComas AJ, Jørgensen PB, Upton ARM. The neuropraxic lesion: A clinical contribution to the study of trophic mechanisms. Can J Neurol Sci 1974; 1:170-79.

43 W'lliams IR, Gilliatt RW. Regeneration distal to a prolonged conduction block. J Neurol Sci 1977; 33:267-73. 